\title{
Airtightness of Energy Efficient Buildings
}

\author{
M. Kraus, and D. Kubečková
}

\begin{abstract}
The paper deals with the energy performance of buildings with regard to the requirements of Directive 2010/31/EU of the European Parliament and of the Council of 19 May 2010 on the energy performance of buildings. One of the basic principles of energy efficient buildings is perfectly airtight envelope of buildings. Untightness leads to uncontrolled air exchange and increased heat loss. The objective of the paper is to characterize and analyze the airtightness of energy efficient buildings. The analysis is performed on a sample of measurements of energy efficient buildings in the Czech Republic. The sample consists of $50 \mathrm{new}$ buildings built between 2007 and 2011. Each building of the sample fulfills requirements for reduced power consumption with regard to sustainable development.
\end{abstract}

Index Terms - Airtightness, air permeability, energy performance, energy efficient building

\section{INTRODUCTION}

$\mathrm{A}$ CCORDING to laws in force, the construction process is required to be as efficient as possible in terms of energy because the building industry is growing and more and more energy is needed. In EU member states, buildings consume now more than $40 \%$ of energy. In accordance with energy principles which apply with respect to sustainable building processes, measures should be taken which could reduce energy dependence and emissions of carbon dioxide. A reasonable and careful use of energy from non-renewable resources which are now the main source of energy as well as use of alternative natural sources make it possible to reduce considerably consumption of energy and keep sources of energy for future generations in line with principles of sustainable construction. [1-2]

In line with the approved revision of the European Parliament and Council Directive 2010/31/EU on energy performance of buildings of 2010, the European Union member states are required to take measures which will reduce consumption of energy. Among others, it is required to make

Manuscript received July 10, 2013. This work was supported by the specific university research - Student Grant Competition of VSB-TU Ostrava with the ID code SP2013/27 in collaboration with the scientific program called Creation and internationalization of top scientific teams and improvement of their excellence at the Faculty of Civil Engineering VSBTechnical University of Ostrava (CZ.1.07/2.3.00/20.0013).

M. Kraus is with the Faculty of Civil Engineering, VSB - Technical University of Ostrava, Ostrava 70833 Czech Republic (phone: +420 597321 916; e-mail: michal.kraus@vsb.cz).

D. Kubečková is with the Faculty of Civil Engineering, VSB - Technical University of Ostrava, Ostrava 70833 Czech Republic (phone: +420 597321 900; e-mail: darja.kubeckova@vsb.cz). each and every effort to comply with commitments resulting from the Kyoto Protocol on Climate Changes and to keep the increase of global temperature below $2{ }^{\circ} \mathrm{C}$ as well as the commitment to reduce by 2020 total emissions of greenhouse gases at least by $20 \%$ against values of 1990 . [1-2]

Airtightness, this means the ability of the building envelope not to let in/out the air, is among key preconditions for energy efficient constructions which may reduce energy performance of the buildings. Except for the EU countries in the south of Europe, in the typical climate the temperatures of air inside the building are, for most days of the year, higher than the temperature of the outdoor air. Undesirable air leakage from buildings, both new build and existing, is a major cause of energy loss and increasing greenhouse gas emissions. If the building envelope is not airtight enough, heat escapes most of the year from the inside to the outside through cracks, joints and leaks. The heat typically escapes in connections of structures and materials. If the building envelope is perfectly airtight, there are not any ventilation gaps and leaks in the external cladding. [2]

\section{THEORETICAL BACKGROUND}

The dependence of the flow of air through the building envelope is defined by the equation of flow, so called building leakage curve:

$Q=C \cdot \Delta p^{n}$,

Where $\mathrm{Q}$ is the leakage air volume flow rate $\left[\mathrm{m}^{3} / \mathrm{h}\right], \mathrm{C}$ is the flow coefficient $\left[\mathrm{m}^{3} /(\mathrm{h} \cdot \mathrm{Pa})\right], \Delta \mathrm{p}$ is he pressure difference between inside and outside of the building $[\mathrm{Pa}]$ and $\mathrm{n}$ is the flow exponent [-]. [3-5]

The flow coefficient $\mathrm{C}$ and the flow exponent $\mathrm{n}$ depend directly on the building envelope. These variables determine how much air and how air flows through leaks in the building envelope. The flow coefficient $\mathrm{C}$ is equals to the air volume flow rate with a pressure difference of $1 \mathrm{~Pa}$. The flow exponent $\mathrm{n}$ is characterized by airflow. The flow exponent $\mathrm{n}$ is normally found to be in the vicinity of 0.67 but has the limiting values of 0.5 (turbulent flow) and 1 (laminar flow) from simple physical considerations. [3,5]

Figure 1 illustrates plot of pressure difference in a logarithmic scale on the leakage air volume flow rate. The value of the flow exponent corresponds to the slope of the line. The flow exponent $\mathrm{n}$ indicates its angle: 
$n=\operatorname{tg} \alpha$

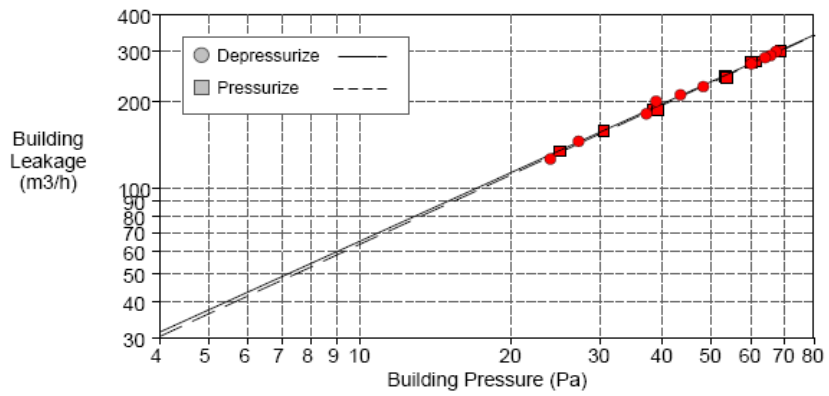

Fig. 1. The dependence of the pressure difference on the leakage air volume flow rate in measurements of air passage through the building envelope [22]

\section{BUILDING AIR PERMEABILITY}

Airtightness of the building envelope is characterized by air leakage through the external cladding. The air leakage of the building can be defined as out-of-control exchange of air by leaks in the external cladding where such leaks negatively influence energy balance of the building. The lower the air leakage of the building is, the higher the airtightness is. [2]

Air leakage is quantified as air change rate per hour. It is measured at a reference pressure difference of $50 \mathrm{~Pa}$ between the inside and outside of the building. The value of $n_{50}$ expresses airtightness in numbers, and indicates how often the air volume of the building concerned is exchanged per hour at a pressure difference of $50 \mathrm{~Pa}$. The value of $\mathrm{n}_{50}$ equals to 0.60 means that a maximum of $60 \%$ of the complete building air volume can escape per hour. The air change rate is defined as a ratio of the leakage air volume flow rate of a fan with a pressure difference of $50 \mathrm{~Pa}$ and the internal volume of the building under assessment:

$n_{50}=\frac{Q}{V}$,

where $\mathrm{n}_{50}$ is the air change rate per hour with pressure difference of $50 \mathrm{~Pa}[\mathrm{ACH}], \mathrm{Q}$ is the leakage air volume flow rate of a fan with a pressure difference of $50 \mathrm{~Pa}\left[\mathrm{~m}^{3} / \mathrm{h}\right]$ and $\mathrm{V}$ is the internal volume of the building $\left[\mathrm{m}^{3}\right]$. [6]

In many countries, for instance in UK, France or Switzerland, the airtightness is now described by air permeability $\mathrm{q}_{50}$. The air permeability is the ratio of the leakage air volume flow rate of a fan with a pressure difference of $50 \mathrm{~Pa}$ and an equivalent surface area of the internal volume. The air permeability, unlike the air change rate, takes into account not only the size, but also the shape of the building under assessment:

$q_{50}=\frac{Q}{A_{e}}$,

where $q_{50}$ is the air permeability for the pressure difference of
TABLE I

UNITS FOR AIRFLOW AND AIRTIGHTNESS

\begin{tabular}{lll}
\hline \hline Symbol & Quantity & Unit $^{1}$ \\
\hline$Q$ & leakage air volume flow rate & $\mathrm{m}^{3} / \mathrm{h}$ \\
$C$ & flow coefficient & $\mathrm{m}^{3} /(\mathrm{h} \cdot \mathrm{Pa})$ \\
$\Delta \mathrm{p}$ & pressure difference & $\mathrm{Pa}$ \\
$\mathrm{n}$ & flow exponent & - \\
$\mathrm{n}_{50}$ & air change air per hour at $50 \mathrm{~Pa}$ & $1 / \mathrm{h}$ or ACH \\
$q_{50}$ & air permeability at $50 \mathrm{~Pa}$ & $\mathrm{~m}^{3} /\left(\mathrm{h} \cdot \mathrm{m}^{2}\right)$ \\
$w 50$ & & \\
$E L A$ & equivalent leakage area & $\mathrm{cm}^{2}$ \\
$N L$ & normalized leakage area & - \\
$V$ & internal volume & $\mathrm{m}^{3}$ \\
$A_{e}$ & envelope area & $\mathrm{m}^{2}$ \\
$A_{f l o o r}$ & floor area & $\mathrm{m}^{2}$ \\
$P_{r}$ & reference pressure & $\mathrm{Pa}$ \\
$\rho$ & density of air & $\mathrm{kg} / \mathrm{m}^{3}$ \\
\hline \hline
\end{tabular}

$50 \mathrm{~Pa}\left[\mathrm{~m}^{3} /\left(\mathrm{h} \cdot \mathrm{m}^{2}\right)\right], Q$ is the volumetric flow rate of a fan at 50 $\mathrm{Pa}\left[\mathrm{m}^{3} / \mathrm{h}\right]$ and $\mathrm{A}_{\mathrm{e}}$ is the envelope area of the building $\left[\mathrm{m}^{2}\right]$. [6]

Because different definitions are used for airtightness of the building in various countries, it is rather complicated to make comparison between the countries. If the volume and envelope surface to be cooled down in the heated space are known, it is possible to make conversion, using the relation between the air change rate and air permeability:

$q_{50}=n_{50} \cdot \frac{V}{A_{e}}$,

where $\mathrm{q}_{50}$ is the air permeability at $50 \mathrm{~Pa}\left[\mathrm{~m}^{3} /\left(\mathrm{h} \cdot \mathrm{m}^{2}\right)\right], \mathrm{n}_{50}$ is the air change rate at $50 \mathrm{~Pa}[\mathrm{ACH}], \mathrm{V}$ is the internal volume of the building $\left[\mathrm{m}^{3}\right]$ and $A_{e}$ is the envelope surface area of the building $\left[\mathrm{m}^{2}\right]$. [7]

Airtightness of the building envelope can also be expressed in a specific flow rate, equivalent leakage area and normalized leakage area. Specific flow rate $\mathrm{w}_{50}$ is defined as air flow through the building envelope at $50 \mathrm{~Pa}$ divided by the floor area at pressure difference of $50 \mathrm{~Pa}$ :

$w_{50}=\frac{Q}{A_{\text {floor }}}$,

where $\mathrm{w}_{50}$ is the specific flow rate at pressure difference of 50 $\mathrm{Pa}\left[\mathrm{cm}^{2}\right], \mathrm{Q}$ is the leakage air volume flow rate of a fan with a pressure difference of $50 \mathrm{~Pa}\left[\mathrm{~m}^{3} / \mathrm{h}\right]$ and $\mathrm{A}_{\text {floor }}$ is the floor area $\left[\mathrm{m}^{2}\right] .[3,8]$

Equivalent leakage area ELA is characterized by the area of an orifice which would have the same leakage as the building at $4 \mathrm{~Pa}$ or $10 \mathrm{~Pa}$ pressure difference. Normalized leakage area is normalized leakage area with the floor area of the building:

$E L A=\frac{Q}{\sqrt{\frac{2 \cdot P_{r}}{\rho}}}$, 
where ELA is the equivalent leakage area $\left[\mathrm{cm}^{2}\right], \mathrm{Q}$ is the volumetric flow rate of a fan at $50 \mathrm{~Pa}\left[\mathrm{~m}^{3} / \mathrm{h}\right], \mathrm{P}_{\mathrm{r}}$ is the reference pressure $[\mathrm{Pa}]$ and $\rho$ is the density of air $\left[\mathrm{kg} / \mathrm{m}^{3}\right]$. [8]

\section{Checking Airtightness of the Building EnVElope}

The check of airtightness of the building envelope should be an integral part of each building. The air passage and leaks in the external cladding can be determined using the Blower Door Test. Principles of this test are very simple. A calibrated fan is installed into an opening, typically into an entrance door or window. The fan creates pressure or overpressure in the building. The fan is connected through an automatic control unit to a PC which automatically starts and evaluates the measurement. [9]

The airtightness can be measured automatically, using software which is supplied along with the airtightness measuring unit, for instance TECTITE Express [22]. The software processes data and plots charts, showing dependence of the fan flow rate $\left[\mathrm{m}^{3} / \mathrm{h}\right]$ on intervals entered for the pressure difference $[\mathrm{Pa}]$. It is possible then to fit a regression curve through the obtained points and, in turn, to evaluate the air change rate $\mathrm{n}_{50}$ or air permeability $\mathrm{q}_{50}$ for the pressure difference of $50 \mathrm{~Pa}$ in line with relations above.

\section{IMPORTANCE OF AIRTIGHTNESS}

Undesirable and uncontrolled leakage of air from the inside through the building envelope to the outside will reduce efficiency of the thermal insulation, reduce heat resistance of the structure and increase losses by ventilation. The increased losses by ventilation directly increase the heat demand for heating purposes. High consumption of energy for operation negatively influences economy. [10]

Forced ventilation with heat recovery is planned in order to have fresh air supplies and to fulfil health requirements for the energy efficient buildings. Too much passage of air through the external cladding influences negatively and reduces efficiency of the heat recovery system.

If the envelope is not airtight enough, the energy demand will increase and there will be also a risk that the envelope structure will degrade and shorten its service life. The pressure difference causes the moist air to leak from the inside through joints into the envelopment structure, which may, in turn, result in water vapors condensing and fungal growth. [11]

\section{Airtightness of ENERGy EFFicient BuiLdings}

The 50 energy efficient buildings are chosen to analysis. The whole group of buildings is a random sample of energy efficient buildings in the Czech Republic. Buildings are different from each other in, among other things, year of construction, construction type, size and shape. All the buildings were built in years between 2007 and 2011. All analyzed energy efficient buildings were designed and constructed in accordance with the rules of the Passive House Institute (PHI) [12] in Darmstadt, Germany.
Figure 2 is a plot of histrogram air change rate per hour at $50 \mathrm{~Pa}$ with the cumulative curve. It is clear more than $90 \%$ of all buildings has air change rate per hour at $50 \mathrm{~Pa}$ less than 0.6 $\mathrm{ACH}$. The value of $0.6 \mathrm{ACH}$ is the maximum value for the energy passive houses according to Passive House Institute.

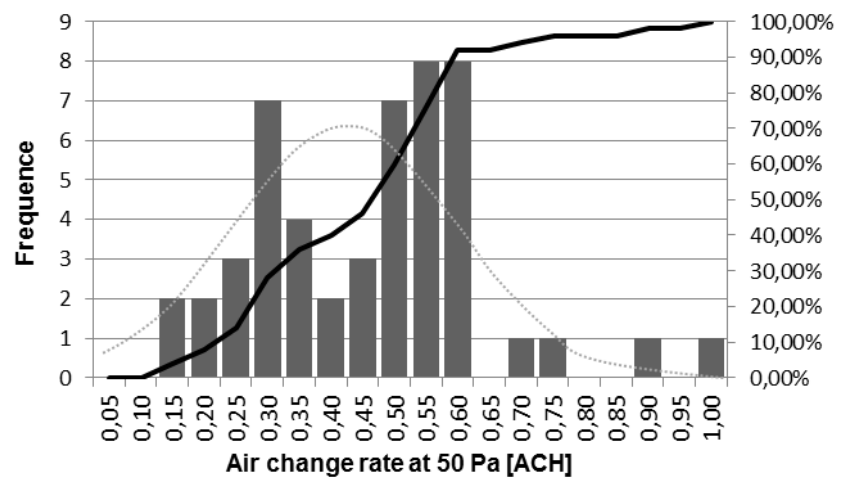

Fig. 2. Histogram of freguence for air change rate at $50 \mathrm{~Pa}$ with the cumulative frequence [24]

The mean air change rate at $50 \mathrm{~Pa}$ is $0.44 \mathrm{ACH}$, with standard error 0.03 . The highest value is $1.00 \mathrm{ACH}$, and the lowest is $0.13 \mathrm{ACH}$. The detailed results of the exploratory data analysis illustrate Tab II.

TABLE II

EXPLORATORY DATA ANALYSIS [23]

\begin{tabular}{lrl}
\hline \hline & Statistic & Std. Error \\
\hline Mean & 0.4412 & 0.0254 \\
Median & 0.4650 & \\
Variance & 0.0300 & \\
St. Deviation & 0.1798 & \\
Minimum & 0.1300 & \\
Maximum & 1.0000 & \\
Range & 0.8700 & \\
Skewness & 0.6240 & 0.3370 \\
Kurtosis & 0.9500 & 0.6620 \\
\hline \hline
\end{tabular}

\section{A. Year of Construction}

There are only recommended values of building airtightness in the Czech Republic. For this reason, not everyone building has a measured value of air change rate at pressure difference $50 \mathrm{~Pa}$.

Increased interest in measuring the airtightness of energy efficient buildings evoked The Green Savings programme of Ministry of the Environment in 2009. The Green Savings programme focuses on support for investment in energy savings in reconstructions and new buildings. The program Green Savings programme established the conditions for financial support to construction of energy passive houses. One of the many conditions is also a requirement to achieve the air change rate at $50 \mathrm{~Pa} 0.60 \mathrm{ACH}$, as set out in TNI 73 0329 [13] for the construction of energy passive house. [14]

The Green Savings program was suspended for new applications at the end of 2010. Since, it is possible to observe a noticeable decline in demand for airtightness measurement of the energy efficient buildings. 
Currently, Green Savings program is started again. In this situation it is possible to expect a renewed interest in measurement of the airtightness of the energy efficient buildings.

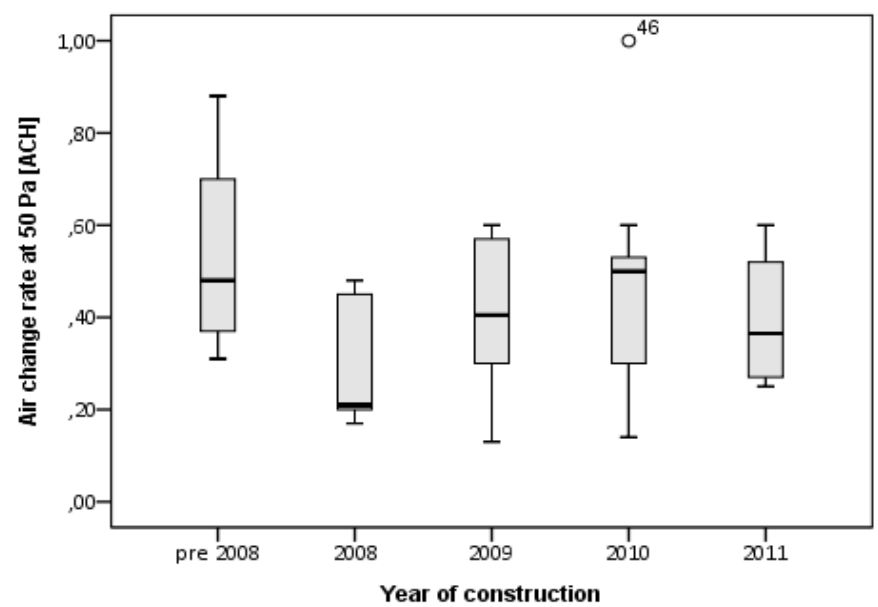

Fig. 3. Airitghtness of energy efficient buildings grouped by years [23]

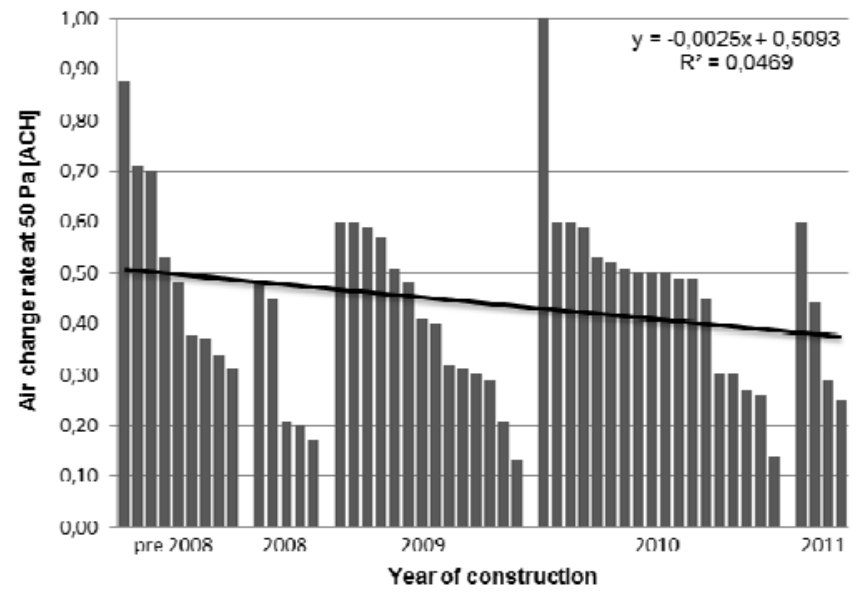

Fig. 4. Airitghtness of energy efficient buildings grouped by years [24]

Plots shown in Figures 3 and 4 ilustrate the dependence of the building airtightness on year construction. There is a slight but not a significant trend of newer buildings being more airtight than the older ones. The number of buildings is relatively small for definite conclusions. The decrease represents trendline in Figure 4.

\section{B. Construction type of the building}

Some of the studies and analyzes show $[6,15]$ that there is a statistically significant difference between the building airtightness and construction type.

Figure 5 is a plot of the air change rate per hour at $50 \mathrm{~Pa}$ versus building construction type. According boxplot is possible to deduce statistical influence on the type of construction airtightness of buildings. The highest values have mixed construction, and the lowest values have masonry construction. Masonry constructions are tighter than lightweight timber-frame constructions
However, according to Kraus $[2,9,16]$, there is no statistically significant relationship between construction type and airtightness of energy efficient buildings. Independence was verified using one-way analysis of variance and Kruskal Wallis test.

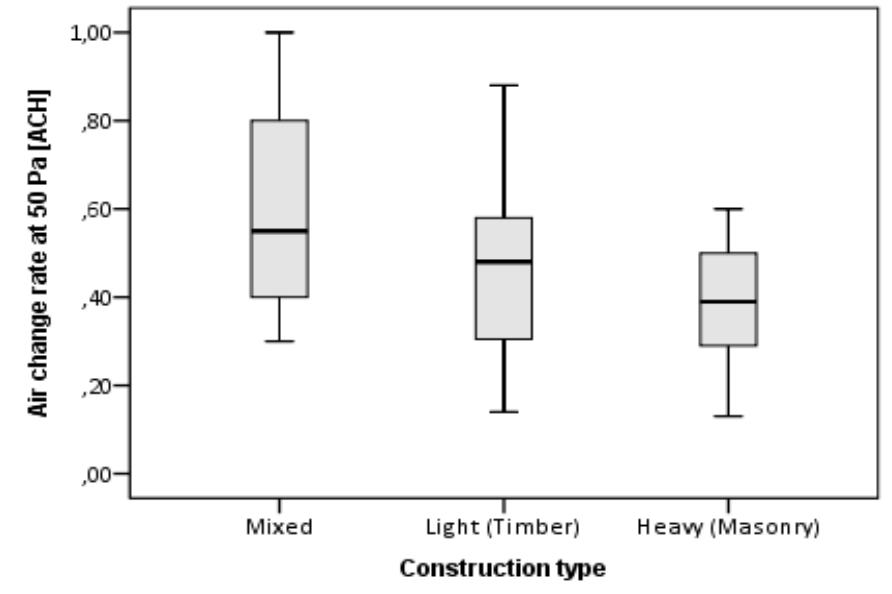

Fig. 5. Airitghtness of energy efficient buildings grouped by construction type [23]

\section{INFLUENCE OF BUILDING'S PARAMETERS ON AIRTIGHTNESS}

When calculating the airtightness of the building, it is essential to take into account not only the leakage air volume flow rate of a fan with the pressure difference of $50 \mathrm{~Pa}$, but also other parameters of the building.

The equations 3, 4 and 6 describe the airtightness of the building in different ways and consider the internal volume, the envelope area or the floor area of the building. The purpose of this paper is to analyses and verifies whether those parameters play a statistically relevant role for the final airtightness of the building.

\section{A. Internal volume of the building}

The internal volume of a heated space, $\mathrm{V}\left[\mathrm{m}^{3}\right]$, is the volume of air in the zone of the heated building. Figure 6 is a plot of internal volume versus air change rate at $50 \mathrm{~Pa}$.

The internal volume is sometimes replaced by a building volume. The building volume is the total volume of the building defined by external dimensions of the building. The enclosed space contains the envelope and internal structures. The building volume must be multiplied by a factor (typically 0.80 ) to obtain the internal volume of the building. 


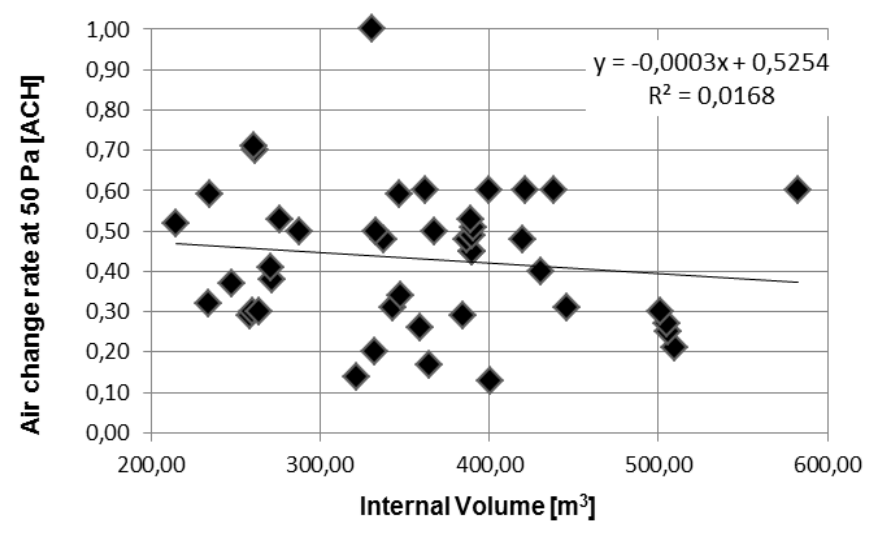

Fig. 6. Internal volume of the building versus air change rate at $50 \mathrm{~Pa}$ [24]

\section{B. Envelope are of the building}

The envelope area, $A_{e}\left[\mathrm{~m}^{2}\right]$, is the sum of all envelope structures which are being cooled down between the heated zone and the outdoors/unheated space. Figure 7 describes the dependence of the envelope are for air change rate at $50 \mathrm{~Pa}$.

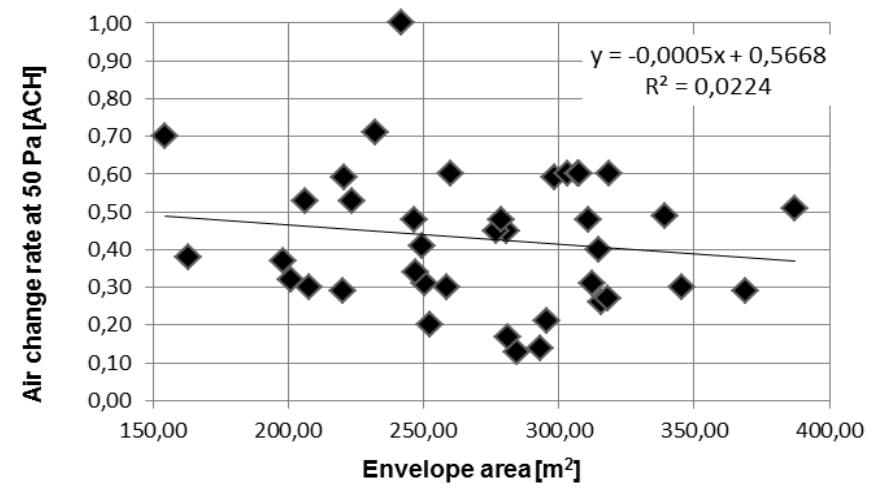

Fig. 7. Envelope are of the building versus air change rate at $50 \mathrm{~Pa}$ [24]

\section{Floor area of the building}

The floor area, $A_{\text {floor }}\left[\mathrm{m}^{2}\right]$, is measured inside the external walls but does not comprise components which mark borders of the building. The use floor area in a residential building comprises areas which are used as a kitchen, living room, bedroom, bathroom, basements and common areas which are used jointly by all owners of accommodation units. Figure 8 shows dependence of the floor area on air change rate at 50 $\mathrm{Pa}$.

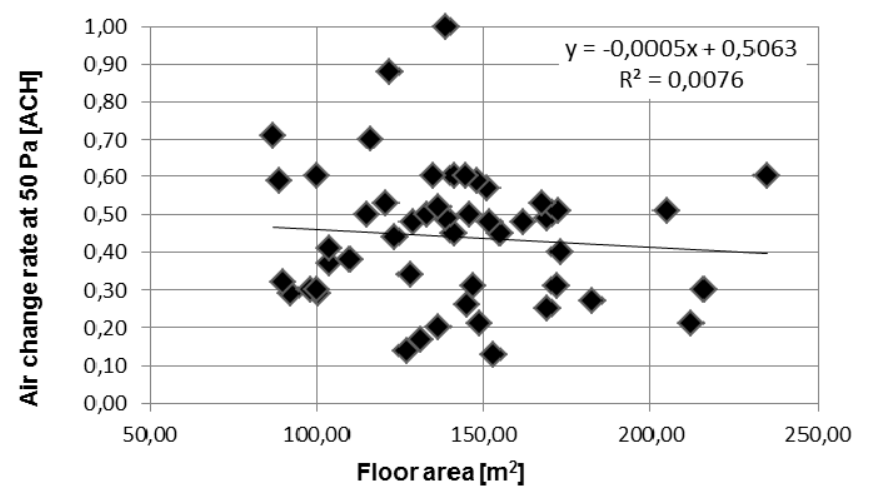

Fig. 8. Floor are of the building versus air change rate at $50 \mathrm{~Pa}$ [24]

\section{Validation of the Sample Normality}

In order to choose a suitable statistic method which will validate the hypothesis of dependencies, it is necessary to check first normality of the variables. For this purpose, a statistic survey of the normality test should be carried out. This test will reveal whether the data file of the random variable corresponds to Gaussian normal distribution of probability.

The normality of the sample can be checked by Kolmogorov-Smirnov tests for one choice. The purpose of the Kolmogorov-Smirnov test is to validate the $\mathrm{H}_{0}$ hypothesis with the relevance level of $\alpha=0.05$ (5\%). The hypothesis is that the random sample of an interval for $n$ elements originates from the basic file with normal distribution where the distribution function is $\mathrm{F}(\mathrm{x})$. Let us define the zero and alternative hypotheses:

- $\mathrm{H}_{0}$ : The sample originates from the basic file with normal distribution.

- $\mathrm{H}_{\mathrm{A}}$ : The sample does not originate from the basic file with normal distribution. [17]

TABLE III TEST OF NORMALITY [49]

\begin{tabular}{llll}
\hline \hline Kolmogorov-Smirnov $^{\mathrm{a}}$ & statistic & df & Sig. \\
\hline $\mathrm{V}$ & 0.105 & 44 & $0.200^{*}$ \\
$\mathrm{~A}_{\mathrm{e}}$ & 0.103 & 39 & $0.200^{*}$ \\
$\mathrm{~A}_{\text {floor }}$ & 0.094 & 50 & $0.200^{*}$ \\
\hline \multicolumn{2}{c}{$*$ This is a lower bound of the true significance. }
\end{tabular}

The normal distribution of probability of the sample file is the precondition for selection of parametric tests of dependencies. If $\mathrm{p}$-value is greater than the level of relevance, $\alpha$, the zero hypotheses, $\mathrm{H}_{0}$, cannot be ruled out and the following relation is assumed to be valid:

$p-$ value (Sig.) $>\alpha$.

Table III shows results of the Kolmogorov-Smirnov test of normality by means of a statistics editor IBM SPSS Statistics ver. 19.0.0 [49]. In this case, $\mathrm{p}$ - value (Sig.) is for each sample greater than the level of relevance, $\alpha=0.05$, and the zero hypotheses, $\mathrm{H}_{0}$, can be accepted. The alternative hypothesis, $\mathrm{H}_{0}$, is assumed to be valid and parametric testing of hypothesis should be used for verification of dependencies.

\section{E. Correlation Analysis}

The correlation analysis is used to determine closeness of dependence (the strength of relation) of two continuous random variables. Two random variables correlate, if certain values of one variable tend to co-occur jointly with certain values of the other variable. [18]

The closeness of two random variables can range from complete absence of correlation (all values of $\mathrm{Y}$ occur with the same probability with any value of $\mathrm{X}$ ) to absolute correlation (for each value $\mathrm{Y}$, there is an only one value of $\mathrm{X}$ ). 
[18]

There are several correlation coefficients which describe, in terms of quantity, the closeness of relation between two correlated quantities. The degree of relation pursuant to Table IV can be used to interpret the correlation coefficient of dependence between two variables. [19]

TABLE IV

INTERPRETING STRENGTH OF CORRELATION COEFFICIENT [19]

\begin{tabular}{lll}
\hline \hline Coefficient & Strength (relationship) & Alternative description \\
\hline 0.00 & No association & \\
$0.01-0.09$ & Trivial & Very small, practically zero \\
$0.10-0.29$ & Low to moderate & Small, low, minor \\
$0.30-0.49$ & Moderate to substantial & Medium \\
$0.50-0.69$ & Substantial to very strong & Large, High major \\
$0.70-0.89$ & Very strong & Very large, very high, huge \\
$0.90+$ & Near perfect & \\
\hline \hline
\end{tabular}

When calculating the strength of relation between two variables by means of correlation coefficients, it is necessary to take into account that the correlation analysis distinguishes between the dependent variables and independent variables. The correlation does not pay attention to the fact whether $\mathrm{X}$ depends on $\mathrm{Y}$ or whether $\mathrm{Y}$ depends on $\mathrm{X}$. No attention is paid at all to dependence of variables during correlation. Or it is the author who should make such decision on the basis of his or her practical experience. Correlation between two continuous random variables, $\mathrm{X}$ and $\mathrm{Y}$, with normal distribution of probability and the degree of closeness of the relation are described using the Pearson correlation coefficient. [19]

The Pearson correlation coefficient uses in calculations the rank of values of the variables and assumes normality of data. Pearson correlation coefficient is a measure of linear association. [20]

Values of the Pearson correlation coefficient of the parametric correlation, $\mathrm{r}$, range between $<-1 ; 1>$. The higher the absolute value $r$ is the close the dependence between two variables is. The positive correlation coefficient describes a positive (increasing) correlation, while a negative correlation coefficient describes a negative (decreasing) correlation. If the correlation coefficient is zero, the variables are randomly ranked without any dependence. [19, 20]

TABLE V

PARAMETRIC PEARSON CORRELATION COEFFICIENT [23]

\begin{tabular}{llr}
\hline \hline $\begin{array}{l}\text { Pearson } \\
\text { Correlation }\end{array}$ & & $\mathbf{n}_{\mathbf{5 0}}$ \\
\hline & Correlation Coefficient & -0.130 \\
$\mathrm{~V}$ & Sig. (1-tailed) & 0.201 \\
& $\mathrm{n}$ & 44 \\
& Correlation Coefficient & -0.149 \\
$\mathrm{~A}_{\mathrm{e}}$ & Sig. (1-tailed) & 0.182 \\
& $\mathrm{n}$ & 39 \\
& Correlation Coefficient & -0.087 \\
$\mathrm{~A}_{\text {floor }}$ & Sig. (1-tailed) & 0.273 \\
& $\mathrm{n}$ & 50 \\
\hline \hline
\end{tabular}

Table V shows the Pearson correlation coefficients for the airtightness of the building, where the variable is represented by the air change rate at $50 \mathrm{~Pa}$, and parameters of the building. The parametric correlation is calculated in IBM SPSS Statistics ver. 19.0.0 [23].

The values of the correlation coefficient as very small and some are even zero. The strength of relation of the variables is trivial and almost does not exist in terms of statistics. According to Table $\mathrm{V}$, the relation is most close for the following pair of variables: air change rate at $50 \mathrm{~Pa}$, and the envelope area.

\section{F. Determination Coefficient}

The determination coefficient, $d$, is used to clarify clearly the dependence between two coefficients. The determination coefficient, $d$, is typically expressed in per cent and is defined as a square of the correlation coefficient multiplied with 100 . The determination coefficient defines the percentage through which the parameter contributes to the final effect [21]:

$d=r^{2} \cdot 100$.

According to Table VI, the determination coefficients are very low and, in terms of statistics, those factors do not contribute to the final airtightness of the building.

The building envelope area influences the airtightness at most. The envelope's contribution to the airtightness of the building is $2.220 \% .97 .780 \%$ of the airtightness is influenced by other factors than the envelope surface area of the building.

TABLE VI

DETERMINATION COEFFICIENT [23]

\begin{tabular}{lcr}
\hline \hline Parameters & Correlation Coefficient & Determination Coefficient \\
\hline $\mathrm{V}$ & -0.130 & $1,690 \%$ \\
$\mathrm{~A}_{\mathrm{e}}$ & -0.149 & $2,220 \%$ \\
$\mathrm{~A}_{\text {floor }}$ & -0.087 & $0,757 \%$ \\
\hline \hline
\end{tabular}

\section{CONCLUSION}

The airtight envelope in high quality is among preconditions for energy efficient buildings. Energy savings reached thanks to the properly airtight envelope influence positively the energy balance and are in line with energy measures taken by the European Union states and in line with principles of sustainable construction.

This contribution has tested basic parameters of the building (the internal volume, envelope are and the floor area) as well as statistically relevant influence of those parameters on the airtightness of the building envelope.

Normality of the sample file has been proved for the building parameters and it was possible to make the testing using the parametric correlation with the Pearson correlation coefficient.

The values of the correlation coefficient are very small, almost zero. The determination coefficient which describes, in per cent, the influence on the final quantity is not relevant in terms of statistics. It is the envelope area of the building which 
influences at most the air change rate at 50Pa. The contribution of the envelope area of the final airtightness is $2.220 \%$.

\section{REFERENCES}

[1] "Directive 2010/31/EU of the parlament and of the council of 19 May 2010 on the energy peformance of buildins (recast)", Official journal of the European Union. 2010, L 153, p. 13-35.

[2] M. Kraus, "The importance of passive houses and zero-energy constructions of residential houses with regard on energy development and the requirements in the EU," Thesis of Ph.D. dissertation, Department of Civil Engineering, Faculty of Civil Engineering, VŠB Technical University of Ostrava, Czech Republic, 2013.

[3] J. Novák, Airtightness of building cladding - Vzduchotěsnost obvodových pláštư. Prague: Grada, 2008.

[4] D. Sinnott, and M. Dyer, Air-tightness field data for dwellings in Ireland, Building and Environment. 2011. Doi: 10.1016/j.buildenv.2011.11.016

[5] M. H. Sherman, and R. Chan, Building Airtightness: Research and Practice, Lawrence Berkeley National Laboratory Report No. LBNL53356. Lawrence Berkeley National Laboratory. 2004. Avaible: http://epb.lbl.gov/publications/pdf/lbnl-53356.pdf

[6] Thermal performance of building - Determination of air permeability of buildings - Fan pressurization method, ČSN EN 13829, Prague: Czech Office for Standards, Metrology and Testing, 2001.

[7] University of Exeter, "Air Leakage Testing" in Low Carbon Building Design: Course Notes, retrieved from: http://emps.exeter.ac.uk/media/universityofexeter/schoolofengineeringm athematicsandphysicalsciences/research/cee/lchsmodule1notes/Air_Leak age_Testing.pdf

[8] A. Berge, "Analysis of Methods to Calculate Air Infiltration for Use in Energy Calculations," Master of Science Thesis in the Master's Programme Structural Engineering and Building Performance Design, Department of Civil and Environmental Engineering, Chalmers University of Technology, Göteborg, Sweden, 2011, p. $19-22$.

[9] M. Kraus, and D. Kubečková; "Analysis of Building Airtightness Depending on Contruction System", in Transactions of the VکSB-Technical University of Ostrava, Civil engineering series, No. 1, 2012, Vol. XII, Ostrava: VŠB - Technical University of Ostrava, 2012.

[10] D. Johnston, Low carbon housing - learnig zone. Available: http://www.leedsmet.ac.uk

[11] M. Bauer, P. Mösle, and M. Schwarz, Green Buidling: Guidebook for sustanaible architecture, Berlin: Springer-Verlag, 2010.

[12] Passivehaus Institut, Available: http://www.passiv.de

[13] Simplified calculation methodology and classification of residential buildings with very low heating energy consumption - family houses, TNI 73 0329, Prague: Czech Office for Standards, Metrology and Testing, 2010.

[14] M. Kraus, D. Kubečková and F. Konečný, "Trend in Airitightness of the Buidling Envelope", QUAERE 2012: Reviewed Proceedings of Interdisciplinary International Scientific Conference of PhD Students. Hradec - Králové: Magmanimitas, 2012.

[15] D. Oliver, Air Leakage Standards, Unpublished DTLR Report. 1999.

[16] M. Kraus, M. Černá, B. Hrubá, B. Součková, and D. Kubečková, “ Influence of Building Materials on Building Airtightness, “ Advance Materials Design and Mechanics, to be published.

[17] A. Eydeland, and K. Wolyniec, Energy and Power Risk Management: New Developments in Modeling, Pricing, and Hedging. New Jersey. John Wiley \& Sons, 2002, pp. 70.

[18] A.K. Sharma, Text Book Of Correlations And Regression. New-Delhi: Discovery Publishing House, 2005.

[19] D. A. de Vaus, Surveys in Social Research. 5rd ed., London: Routledge, 2002, pp. 241-266.

[20] Department of Medical Informatics Institute of Computer Science of the Academy of Sciencesof CR, "chapter 11", Available: http://ucebnice.euromise.cz/index.php?conn=0\&section=biostat $1 \&$ node $=13$

[21] F. N. Kerlinger, Foundations of Behavioral Research. Prague: Academia, 1972.

[22] Software TECTITE Express ver. 3.6.
[23] Software IBM SPSS Statistics ver. 19.0.0.

[24] Software Microsoft Office Professional 2010 Excel ver. 14.0.6129.500

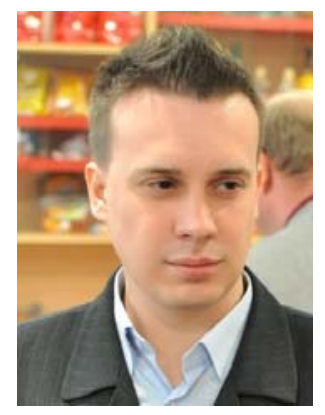

Michal Kraus (1985, Czech Republic) has graduated from the Faculty of Civil Engineering, VSB - Technical University of Ostrava as a master of Execution of Works in 2011. Since 2011 he has been an internal Ph.D. student at the Department of the Civil Engineering, VSB Technical University of Ostrava in the Czech Republic, field of study Theory of structures. In his research work he focuses in the area of building airtightness and energy efficient buildings. He has published his research paper at several scientific conferences and journal. He has studied one semester at the University of Portsmouth. In 2011 he has actively taken a part as a member of the scientific project Creation and internationalization of top scientific teams and improvement of their excellence at the Faculty of Civil Engineering VSB-Technical University of Ostrava (CZ.1.07/2.3.00/20.0013).

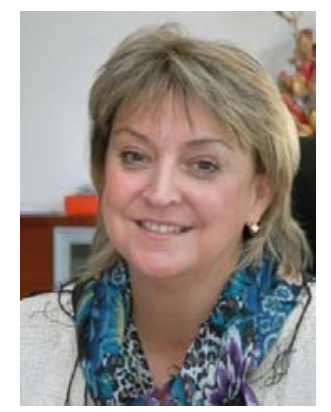

Darja Kubečková (1960, Czech Republic). She graduated from the Faculty of Technology VUT Brno field of Brno in the Czech Republic of Civil engineering in 1987. In 2000 she defended her Ph.D. in the field of Mining and Underground Constructions in the VSB-Technical University of Ostrava in the Czech Republic. At the same university defended the title Associate Professor of Theory and Structures of Buildings with scientific work Defects and faults panel housing construction, in 2010 she became a professor, presented monographs History and perspectives panel construction and was appointed professor in the field Theory and Structures of Buildings. Since 1997 she has worked at the VŠB-Technical University of Ostrava, Faculty of Civil Engineering. In 1997, she worked as Associate Dean for Development and Associate Dean for External Relations. Since 2010, the Dean of the Faculty of Civil Engineering, Head of Department of Construction. In his scientific work focuses on the issue of panel construction, the issue of building defects and failures of building character, building environment and sustainable construction. She is a Certified engineering in the field of building construction and Expert in the field of Construction and Design. In the years 20052012 was a member of the Research center CIDEAS (Centre for Integrated Design of Advanced Structures) and leading research groups in solving problems with building energy design of buildings industrial settlements and their conversion. She is author of numerous publications and the author of 3 monographs, investigator scientific research projects. She is a member of the Scientific Council of the Faculty of Mining and Geology VSB-TU Ostrava, an honorary member of the Scientific Board of the Faculty of Civil Engineering in Brno, Prague, Bratislava, Kosice and Zilina in Slovakia. It is also a member of the Czech Society for Sustainable Building, a member of the editorial board of the Journal Mshenebloba, 1.st Vice President Moravian timber cluster in Ostrava, Member of the Supervisory Board of the Regional Energy Agency in Ostrava, was awarded the rector of the VŠB-TU Ostrava for Development. 